\title{
Hazardous-waste containers in cementitious materials: leakage test on small-scale specimens and on full-scale prototypes
}

\author{
A. Taglioni ${ }^{1}$, A. Castellani ${ }^{2}$ \& P. De Stefanis ${ }^{1}$ \\ ${ }^{1}$ ENEA, Italy \\ ${ }^{2}$ Politecnico di Milano, Department of Structural Engineering, Italy
}

\begin{abstract}
A modular system for containment of nuclear waste packages based on two barriers of cementitious materials was designed for a repository of radioactive substances, and then investigated in order to test leachability in a period of time of 300 years. Cement agglomerates designed for the isolation of dangerous waste exhibit low permeability, hence a favourable durability, that appoints them as proper material for construction of hazardous waste in general, i.e. toxic, medical, or radioactive waste. Characterisation of suitable concrete mix design has been attained through leakage tests, carried out on a concrete slab $300 \times 300$ $\mathrm{mm}$ wide. Four full-scale prototypes of the system were then built from the same concrete mix, and were submitted to a test of waterproofing at a laboratory. Experimental evidence on two weak points has been collected. One, of a general character, is related to the almost unavoidable presence of "construction joints", a second weak point is related to non-homogeneity of concrete. Then two different design procedures were suggested.
\end{abstract}

Keywords: disposal, concrete leakage, dangerous waste, radioactive waste.

\section{Introduction}

Over the last decades, the role of cementitious materials has developed from structural building materials to comprise cement-based matrices providing environmental control of hazardous contaminant release. 
A typical repository for radioactive substances, encapsulated in drums, is described in the following. It is based on three barriers made of cementitious materials. Any one of the three barriers may play two different roles: it provides structural resistance against various kind of possible intrusions, and it may provide control of hazardous contaminant release. The long-term efficacy of the treatment process largely depends on the durability of the treated material in its environmental scenario. Thus, it has become significant to understand and predict the relationship between constituent release and physical durability of the cement matrix. The class of cement agglomerates designed for the isolation of dangerous waste typically displays low permeability, which is the characteristic of cementitious materials capable to lead to a favourable durability. This class is thus appointed as proper material for hazardous waste in general, i.e. toxic, medical, or radioactive waste.

In the repository-system, a sub-system is represented by the "module": a modular reinforced-concrete container in which the drums are immobilized in a cement mortar. Four full-scale prototypes of this sub-system, of approximately $10 \mathrm{~m}^{3}$, were then built and submitted to a test of waterproofing and experimental evidence on two weak points in such a procedure has been collected. One, of a general character, is related to the nearly unavoidable presence of "construction joints", even those that are hardly noticeable at a view inspection. They can be the reason of the lack of liquid tightness. A second weak point is related to the particular requirements of the prototypes: thin wall thickness and a relative reinforcement congestion have suggested to avoid concrete vibration and to rely on superplasticizers to cast the prototypes. Sonic surveys helped tracing in detail the lack of homogeneity in the concrete walls and slab.

\section{Typical waste repository}

Since long times, the nuclear industry has been studying and developing solution for the final disposal of waste. For low and intermediate activity waste already produced in Italy, a concept design was developed for the final repository. It is a so-callled "near-surface" engineered solution, based on man-made barriers, opposite to the "geologic" solution, which basically relies on the isolation capability of soils/rocks. Radioactive wastes have different activity levels, depending on the species contained. The ones with most activity (or long-lived) are produced by nuclear power plants and can be incorporated into a glass matrix (vitrified) and then sealed in steel containers, while those of low and intermediate activity, mostly short-lived, are conditioned in metallic drums of various dimensions.

Drums are kept in place by pouring a cement mortar (grout) in a caisson of reinforced concrete (modular containers), as in Figure 1 (a); the modular containers are disposed in reinforced concrete buildings, called 'repository units', shown in Figure 1 (b).

The grout guarantees the compete filling of waste containers. Under such conditions, as a three-dimensional solid without voids, it has an intrinsic mechanical consistence, even if not reinforced. The first barrier offers thus both 


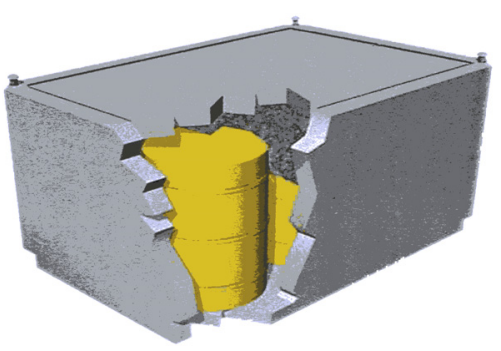

(a)

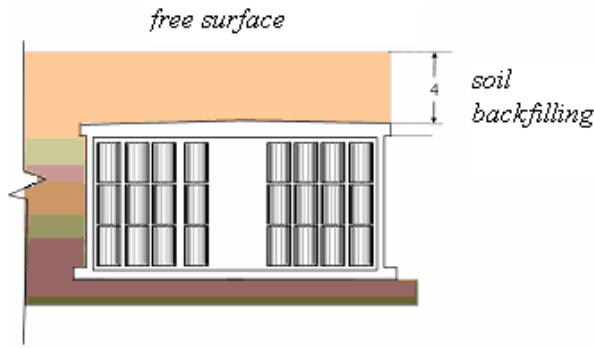

(b)

Figure 1: (a) Drums encapsulating radioactive materials, filling of grout, in the reinforced concrete caisson; (b) repository.

structural resistance and defence towards leakage. The reinforced concrete walls of the modular containers are designed to withstand a number of loading conditions that include intrusions from unknown origin. They too offer structural stability and barrier against leakage. Once the repository units are filled with modular containers, they are covered and buried to provide additional segregation and protection to the system from external injuries. The overall system must assure the containment of radio-nuclides for an estimated period of 300 years, which is considered representative of the decay time of most radionuclides confined in the repository. From that time on the repository will be left in place without surveillance.

Even if the present paper is focussed on low and intermediate radioactive waste, results are of direct interest also for the disposal of highly contaminated hazardous waste that can be stored into metallic drums. Typical hazardous waste can include residues highly contaminated both by organic and by inorganic (mainly heavy metals) pollutants, produced by chemical, metallurgical, tannery, textile and waste treatment industries, as well as waste coming from hospital and research institutes activities. A peculiar application may regard the disposal of hazardous waste highly contaminated by persistent organic pollutants (POPs) such as polychlorinated dibenzo-p-dioxins (PCDDs), chlorinated dibenzofurans (PCDFs) and certain polychlorinated biphenyls (PCBs), better known as "dioxins". By this technique these pollutants can be removed from the environment for a very long time and so their degradation into less harmful compounds can be also promoted.

\section{Selection of the material and design of the module}

A careful study of the mix design lead to the following compositions shown in Table 1 .

The caisson concrete walls are $150 \mathrm{~mm}$ thick and are reinforced with bars of 12 $\mathrm{mm}$ diameter, as it is needed to cope with structural requirements as in Figure 2.

In addition to durability, the concrete module should positively respond to loads applied, in particular to some severe loads identified as the fall from a 150 $\mathrm{cm}$ height during handling and transport. 
Table 1: $\quad$ Grout and module concrete mix designed to minimize leakage.

\begin{tabular}{|l|c|c|}
\hline Components & Concrete (kg/mc) & Grout (kg/mc) \\
\hline Cement CEM III/B 42.5 & 345 & 300 \\
\hline Fly ash (from an electric power Plant) & 100 & 50 \\
\hline Silica fume & 30 & 30 \\
\hline Gravel (Canzian quarry) & 745 & \\
\hline Sand (Canzian quarry) & 980 & 1530 \\
\hline Sand & & 300 \\
\hline Ground limestone & & \\
\hline Viscosity agent & 11.88 & \\
\hline Superplasticizer & 5.89 & 18.27 \\
\hline Polyacrilate superplasicizer & 144 & 144 \\
\hline Water & &
\end{tabular}
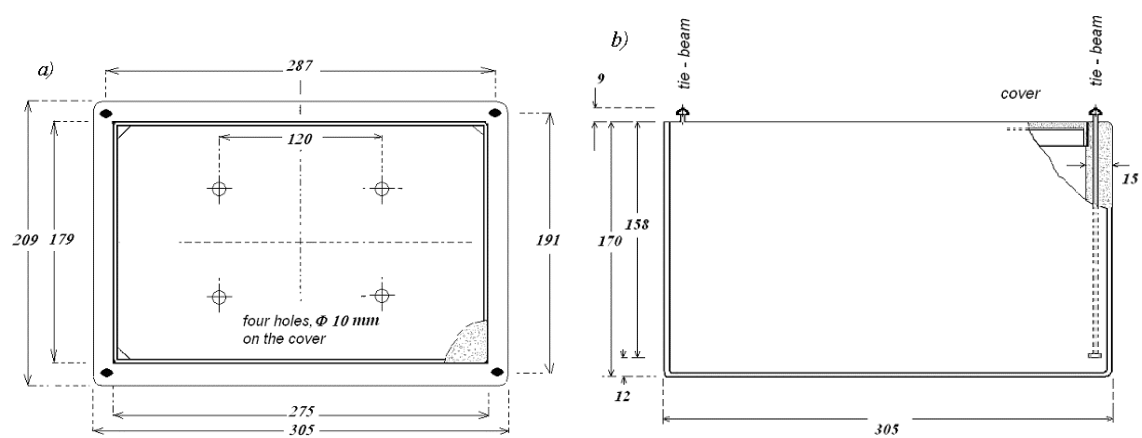

Figure 2: $\quad$ (a) View from top, (b) lateral view (measures in centimetres).

\section{Leaching and leakage, tests on materials}

Imbibition of water develops in two steps: first, water permeates concrete to saturation, and then, provided that pressure gradient is maintained, water starts to flow. Leaching is the selective transport of particles which occurs in a material once seepage of water is established. In a rather conservative approach, it can be assumed that leaching can drag the toxic material, together with the other conditioned in the given matrix. Leaching and leakage have the same meaning for the series of phenomena under examination.

Seepage tests were carried out by measuring the penetration depth of the humid forehead on a slab of concrete $300 \times 300 \times 120 \mathrm{~mm}$, and the water pressure gradient $0,58 \mathrm{bar} / \mathrm{cm}$ (obtained by applying pressure of 7 bars over a slab $12 \mathrm{~cm}$ thick). The concrete depth has been correlated to time $t$ by the relationship

$$
\mathrm{x} \div \sqrt{\mathrm{t}} \text {. }
$$

The increase of water pressure under conditions of concrete integrity does not modify the conclusion. 
After a time period of 120 days, test results and have been interpolated according to the following relationships:

Concrete:

Grout:

$$
\mathrm{x}=0,91(\sqrt{ } \mathrm{t}-1,34)
$$

$$
\mathrm{x}=1,04(\sqrt{ } \mathrm{t})
$$

Where $x(\mathrm{~mm})$ is the penetration depth of water into concrete and $t$ (days) is time since the start of exposure to water,

Using the above relationships, the velocity of the average forehead advance may be extrapolated, as shown in Table 2 .

Table 2: $\quad$ Saturated forehead advance with time in leakage tests on concrete.

\begin{tabular}{|l|c|}
\hline Duration & Penetration depth $\mathbf{( m m )}$ \\
\hline 1000 days & 27,5 \\
\hline 30 years & 94 \\
\hline 300 years & 296 \\
\hline
\end{tabular}

Once the concrete gets saturated, water flows within the concrete mass in a way that can be described by the Darcy law:

$$
Q=\frac{d p}{d r} A k \eta^{-1}
$$

where: $k$ is the hydraulic conductivity, which depends on material characteristics; $\eta$ is water viscosity; $d p / d r$ is the water pressure gradient; $r$ is the abscissa along the slab depth; $A$ is the concrete surface. Tests conducted as in [2] furnished values of the parameter $k$ of the Darcy equation, that vary from $8 \times 10^{-11} \mathrm{~cm} / \mathrm{s}$ to $2,510^{-10} \mathrm{~cm} / \mathrm{s}$.

Permeation occurs through the interconnected pore system within the concrete, i.e., the porosity, and through possible fissures. When present, the latter is the prevailing contribution with respect to the total amount of percolating water. Tests on slabs provide good control over the two permeation effects, allowing a satisfactory control of concrete integrity. In a given concrete, under similar conditions, the hydraulic conductivity is minimal when micro cracks are absent and increases dramatically with crack diffusion and opening. It is therefore concluded that, in order to control leaching and the related properties, it is mandatory to avoid/minimize occurrence of cracking in concrete.

The research has thus identified a concrete mix capable of minimising leakage, maintaining at the same time adequate strength and durability. The above performance characteristics of concrete, leakage, strength and durability, have been found positively correlated in all mixtures.

\section{$5 \quad$ Full scale tests}

Tests have been designed in order to include actual conditions occurring in the construction of a real waste containment structure. 
The difficulty of conciliating workability with the basic properties (minimal leakage, high strength and durability), establishes the difference between laboratory tests on small scale specimens and similar tests on full scale prototype structures. The latter are affected by the defects originated in the construction and provide an essential viewpoint for the qualification of real structures.Because of the bar congestion, to achieve a convenient workability, superplasticizers were added into the mix.

The four containers have been tested in order to provide the following assessments:

1. Identification of possible defects to be ascribed to the construction procedure

2. Evaluation of homogeneity of the concrete castings through ultrasonic tests and tomography

3. Leakage measures

\subsection{Defects ascribed to the construction phase}

The visual inspection of the four modules was carried out on the inner and outer surfaces of the structure, on the cover and bottom and revealed superficial shrinkage cracks, irrelevant to the present scope.

The most important observations, however, are related to construction joints. When fresh concrete is poured on an already hard concrete, a construction joint develops. For most concrete mixtures, the time required the concrete to hard is of the order of the hour, or of a few hours. In presence of superplasticizers it may be of the order of the tens of minutes. In some locations this discontinuity is neatly visible as a line. [3] calls for a particular care in the selection of materials, design, and construction of the form-work, and in the placing and consolidation of the concrete to eliminate bulges caused by construction joints. Since construction joints can also impair the strength of the structure, provision shall be made for transfer of shear and other forces through construction joints.

Except for elementary geometry, interruption in the pouring operation is nearly unavoidable, and it may become critical if interruption lasts for a time of the order of the hardening of concrete. In the present test, attention has been devoted to such discontinuities, and the position of the construction joints likely to occur has been marked for the following control of tightness.

The present research has pointed out that construction joints, even when hardly perceptible, can impair water tightness. Tests give evidence that the wall portions with casting restarts behave as cracked surfaces, even if the openings appears to be of a few micro-meters.

\subsection{Homogeneity of a single casting}

Concrete homogeneity depends on how long concrete remains in the mixer before casting and on the mechanical vibration following the casting. A limiting condition is that presently met, which makes use of superplasticizers to avoid the mechanical vibration. 
Ultrasonic surveys generally allow avoiding coring or destructive testing, in order to track defects such as voids, cracks, casting restarts, detachments, consistency losses of the cement mortar. In the present case, the aim of the test was to measure the elastic modulus and analyse homogeneity with regards to mechanical properties.

The Young modulus has then been evaluated, applying the relationship:

$$
\mathrm{E}=\mathrm{V}^{2} \mu
$$

where $\mu$ is the concrete density and $\mathrm{V}$ is the wave velocity. Young moduli of $32.4 \mathrm{GPa}$ to $50.0 \mathrm{GPa}$ were obtained, with recurrent values in excess of $40 \mathrm{GPa}$. Direct measures of the elastic modulus (modulus at small strain) on cylindrical specimens taken from the module walls confirmed the observed trend, although on a reduced experimental basis.

Tests are necessarily limited to parameters involved in mechanical resistance. It is reasonable however to consider that water tightness is positively related to strength and that its variability is comparable to that observed for the modulus of elasticity.

\subsection{Forehead of the water front in the grout}

In these tests, the spaces allocated to host waste drums were filled with water, coloured with blue-methylene, under 0,3 MPa water pressure, as in figure 3(a). Every three months water has been taken out from the module and sampling of cylindrical concrete specimens $30 \mathrm{~mm}$ diameter was carried out on its bottom and along its walls. The specimens obtained have been subjected to a visual test to observe the propagation of the humid forehead (the blue front), figure 3(b).

The holes in the module were then closed and sealed with a rheoplastic mortar and the module filled again with blue-coloured water.

Test conditions are similar to the small scale slab leakage tests according to ANSI with the following differences:

- Water pressure is 20 times lower.

- Concrete wall is thicker (150 $\mathrm{mm}$ with respect to $120 \mathrm{~mm}$ ).

- Stresses induced by casting in the prototype might have induced small (not visible) cracks.

Considering the differences in wall thickness and pressure gradient, under similar other test conditions, the forehead of water is expected 20 time smaller, so that in one year we should expect $1 \mathrm{~mm}$. By applying Eq. (3), obtained through the tests on slabs, this measure would correspond to $15 \mathrm{~mm}$ in 300 years. Experimental evidence however has not allowed, up to now, a unique interpretation, suggesting again that results obtained from small specimens might not be adequate to represent real constructions when leakage is concerned.

Risk analysis should thus be revisited. In general, it uses block diagrams to describe how components are connected in a larger system. From these block diagrams, the fault-tree technique is developed. When characterization of modular containment is based on the characterisation of the material properties, through experiments on small plates, the probability of failure generally does not incorporate the construction phase. 


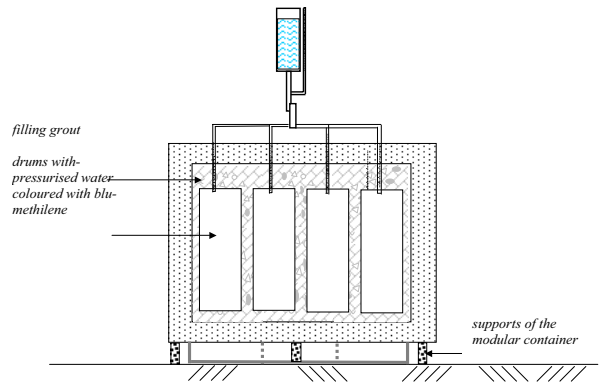

(a)

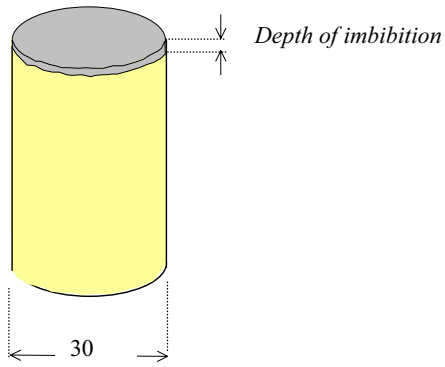

(b)

Figure 3: (a) leakage tests on grout (b) specimen extracted.

\section{Discussion and conclusion}

The principal processes leading to a change of concrete properties as a barrier material are dependent on penetration of atmospheric agents into the concrete mass. Penetration is linked to the porosity of the concrete matrix. Leakage too depends on porosity. Up to now, tests have not provided precise and ready to use information on change of porosity with the time. In the meantime, we make the following assumption: Concretes which guarantee minimal leakage are the ones which best guarantee stability in time and as a consequence, if conditions exist for leakage to manifest, they will be displayed in the short time. As a consequence, for the materials considered, tests run at time zero are representative of their potential in time. Experimental evidence collected in this research can thus be used to predict the behaviour of the structures during the entire nominal lifetime, i.e. some 300 years.

Under this premise, a containment system made up by three barriers, the grout, the modular containment and the repository unit, can be designed according to two different design procedures.

1) Each one of the three barriers guarantees both structural resistance and defence against leakage. A redundancy thus is assured, which is favourable in the theoretical risk analysis. However, a reinforced concrete wall, designed for a strong structural resistance, can survive with some lack of material homogeneity, because in most cases lack of homogeneity does not threaten the structural resistance. However, it may prejudice the defence against leakage. The theoretical risk analysis might disregard such likelihood.

2) Packages are immobilized in a matrix of adequate material, the grout, able to offer the main resistance against leaching. The grout must guarantee the compete filling of waste containers. In this procedure, modular containment walls have a reduced mechanical function, limited to the retrievability of the module. They are not designed against intrusion or falling of the module. Accordingly, reinforcement needs are lowered to the minimum necessary to avoid cracking due to temperature gradients and shrinkage. Precise strength properties are assured by the repository units structures, walls and cover. 
The second approach seems preferable, because each barrier is designed for a single role, and the relevant material shall thus be qualified for a well precise performance. The risk of unexpected failures during the construction phases is thus minimized.

The scenario adopted in this study conservatively considers that the repository units is flooded, although without a precise cause. In fact waste dispersion requires the presence and action of water. However, the tests show that it is possible to design a grout for waste stabilising in a way that the time necessary to dump it in water be of a few centuries. Only after that time, the grout matrix leaching can take place. Such a time interval is consistent with containment requirements for toxic wastes in general.

\section{Acknowledgements}

The experimental study of confining barriers has been promoted by the Italian National Agency for New Technologies, Energy and Environment, ENEA, within the framework of the project on designing a final repository for lowactivity radioactive waste; the mix-design of cementitious materials has been developed by EN.CO., a well known Italian laboratory of concrete, and the tests have been conducted at CESI-Ismes experimental institute.

\section{References}

[1] Taglioni A., Castellani A., Collepardi M., Pellegrino R., Pizzigalli E. (2007): "Hazardous-Waste Containers in Cementitious Materials: Leakage Tests on Small-Scale Specimens and on Full-Scale Prototypes", Studies and Researches, V. 27, pp. 11-32, 2007.

[2] American National Standards, "Measurements of the leachability of solidified low-level radioactive wastes by short-terms test procedure" document ANSI /ANS -16.1-1986.

[3] ACI Committee 350 "Concrete Structures for Containment of Hazardous Materials. American Concrete Institute”, 2004.

[4] European Commission, Nuclear Science and Technology, "The performance of cementitious barriers in repositories", Document EUR 17643 EN, 1998.

[5] Guerrero, A., Hernández M.S., Goñi, S., "Durability of cement-based materials in simulated radioactive liquid waste effects of phosphate, sulphate and chloride ions" J. Mater. Res. pp. 2151-2160, 1998.

[6] Tunaboylu, K., "Safety requirements for the design of large containers for decommissioning waste", Nuclear Engineering and Design, Vol: 159, Issue: 2-3, pp.189-195, November 1, 1995.

[7] Rechard Rob P., "Historical Relationship Between Performance Assessment for Radioactive Waste Disposal and Other Types of Risk Assessment", Risk Analysis, Vol. 19, No. 5, 1999. 